\title{
Preexposure to feeding-related stimuli reduces neophobia
}

\author{
NORMAN S. BRAVEMAN \\ Memorial University of Newfoundland, St. John's, Newfoundland, Canada
}

\begin{abstract}
Rats that were preexposed to novel solutions or to novel feeding environments showed reduced neophobic responses when presented with a familiar solution in a novel container or with a novel flavored solution in a familiar container, respectively. Preexposure to novel solutions also appeared to reduce emotional reactivity as measured in the open field.
\end{abstract}

It has been observed that a rat's natural hesitancy to consume a distinctively flavored novel solution can be disrupted by prior exposure to a similarly flavored solution (Braveman \& Jarvis, 1978; Domjan, 1976), by prior exposure to a distinctively flavored solution whose taste is different from that of the test solution (Braveman \& Jarvis, 1978; Siegel, 1974), or by prior exposure to a series of distinctively flavored solutions none of which resemble the flavor of the test solution (Braveman \& Jarvis, 1978; Capretta, Petersik, $\&$ Stewart, 1975). These latter two findings have been taken to support the notion that the substance to which animals are preexposed is not as important as is the experience with novelty (Braveman \& Jarvis, 1978).

In this vein, Domjan (1976) has argued that prior experience with novelty reduces the aversiveness of subsequent novel tasting solutions and hence increases their acceptability. Indeed, results of experiments by Hennessy, Smotherman, and Levine (1977) and by Weinberg, Smotherman, and Levine (in press) appear to provide additional support for this position. The former of these experiments showed that animals provided with prior exposure to various odors exhibited less taste neophobia than animals with no such experience. Results of the latter experiment show that, in rats, handling during infancy disrupts taste neophobia during adulthood. Thus, it would appear that taste neophobia can be disrupted by a variety of preexposure manipulations, only some of which involve taste or related (e.g., odor) experiences.

\section{EXPERIMENT 1}

That taste neophobia can be reduced in any one of several ways is consistent with the observation, recorded by Domjan (1976), that humans and

I express my thanks to Joan Crane for her able assistance with all phases of this research. These experiments were supported by grants from the Dean of Science, Memorial University of Newfoundland, and from the National Research Council of Canada (No. A-8334) various kinds of animals appear to make positive responses toward stimuli to which they have been previously exposed while, at the same time, avoiding these stimuli when they are novel. Based on findings such as these, he speculated that preexposure may attenuate negative responses which are elicited by novel stimuli. Moreover, he noted that the generality of preexposure effects may indicate that there is a single general mechanism which mediates these diverse effects. One such possibility is that animals that have been preexposed to novel tastes are like those that have been preexposed to novel environmental stimuli (e.g., McCall, Lester, \& Dolan, 1969) in that they are generally less emotionally reactive than animals that have not been preexposed. Since there are no data on the effects of taste preexposure on emotional reactivity, the present experiment was aimed at discovering whether or not taste preexposure reduces emotionality as measured in the open field.

\section{Method}

Subjects. The subjects were 18 experimentally naive male rats of the Long-Evans strain obtained from a commercial breeder. The animals were housed in standard, stainless steel laboratory cages $(19 \times 19 \times 37 \mathrm{~cm})$ that contained wire-mesh floors. The range of weights of the animals at the start of the experiment was between 250 and $300 \mathrm{~g}$.

Apparatus. Solutions presented to the animals in this experiment were tap water, $.75 \%(\mathrm{w} / \mathrm{v})$ coffee, $.15 \%(\mathrm{w} / \mathrm{v})$ sodium saccharin, 3\% (v/v) lemon extract, and 3\% (v/v) almond extract. All solutions were presented to the animals in measured amounts via standard $500-\mathrm{ml}$ water bottles that had been fitted with metal spouts. Open-field testing took place in a circular open field similar to that described by Broadhurst (1957). It consisted of a circular $32-\mathrm{cm}$-high metal enclosure, painted white, which was secured on the outside to a white wooden floor. The diameter of the enclosure was approximately $83 \mathrm{~cm}$. Three concentric circles were painted in black on the floor. Six lines radiated from the perimeter of the innermost circle and transected the middle and outer circle, dividing each of them into six equal segments. Each segment in the outer circle was also divided into two equal parts by lines which radiated from the perimeter of the middle circle to the perimeter of the outer circle. In all, there were 19 segments painted on the floor. A cheesectoth screen, through which observations were made, was mounted around the outside of the fieid in order to reduce extra-field cues. A 100 -W incandescent light was suspended approximately $60 \mathrm{~cm}$ above the floor of the open field. 
A loudspeaker, which emitted constant white noise at $90 \mathrm{~dB}$, was mounted approximately $15 \mathrm{~cm}$ above the light source.

Procedure. Following adaptation to a feeding/drinking schedule, in which animals were handled daily and received ad-lib access to food and $10 \mathrm{ml}$ of tap water per day from their normal drinking bottle for 2 weeks, the animals were randomly assigned to one of three groups. Animals in Group W (water $=6$ ) received eight additional daily presentations of $10 \mathrm{ml}$ of tap water; those in Group $C$ (coffee $=6$ ) received additional daily presentations of $10 \mathrm{ml}$ of the coffee solution; and those in Group V (variable $=6$ ) received two daly presentations of $10 \mathrm{ml}$ each of the coffee, lemon, almond, and saccharin solutions. The sequence of daily presentations was random for each of the animals in Group V.

On Day 23, each animal was removed from its home cage and taken to a separate testing room where it was placed, individually, into the center of the open field for a 5-min test. After each animal was tested, the entire open field was wiped with a detergent solution. Number of segments entered (as defined by the placement of all four feet into a segment), location in the open field (inner circle, middle circle, or outer circle), bouts of grooming (face washing, licking of the anal-genital region), and rearing (raising both forepaws from the floor) were recorded manually throughout the 5-min test period.

\section{Results and Discussion}

The results of the open-field test are summarized in Figure 1 (number of segments entered) and in Table 1 (rearing and grooming). A single-factor ANOVA on the total number of segments entered by animals in the three groups (see Panel A of Figure 1) revealed that the differences were not statistically reliable $[F(2,15)<1]$, indicating that the preexposure manipulations did not have differential effects on overall activity in the open field. When, however, animals' locomotion scores were converted to a ratio by dividing the total number of segments entered in the entire field into the number of segments entered in the middle and inner sections of the open field (Panel B), large differences among the groups emerged. This measure gave an indication of activity within the central part of the open field relative to activity in the outer part. Activity in these two sections of the field have been identified by some investigators as reflecting different levels of emotionality. For example, animals that tend to stay along the wall (i.e., that are positively thigmotaxic) are considered to be timid (e.g., Valle, 1970), while those that are active in the center section of the field are viewed not to be emotional (Ivinskis, 1968).

A single-factor ANOVA on these ratio scores revealed that the differences were highly reliable $[F(2,15)=5.14, p<.01]$. Subsequent NewmanKeuls multiple comparisons on the means of the three groups showed that the relative activity of animals in Group V was higher in the central section of the open field than for either of the other groups (all ps $<.01$ ), while the relative activity in the central segment of the field did not differ for Groups $W$ and C. Inspection of Panel B shows that animals in Groups $\mathrm{W}$ and $\mathrm{C}$ distributed their activity in such a way that they were active in the central section of the
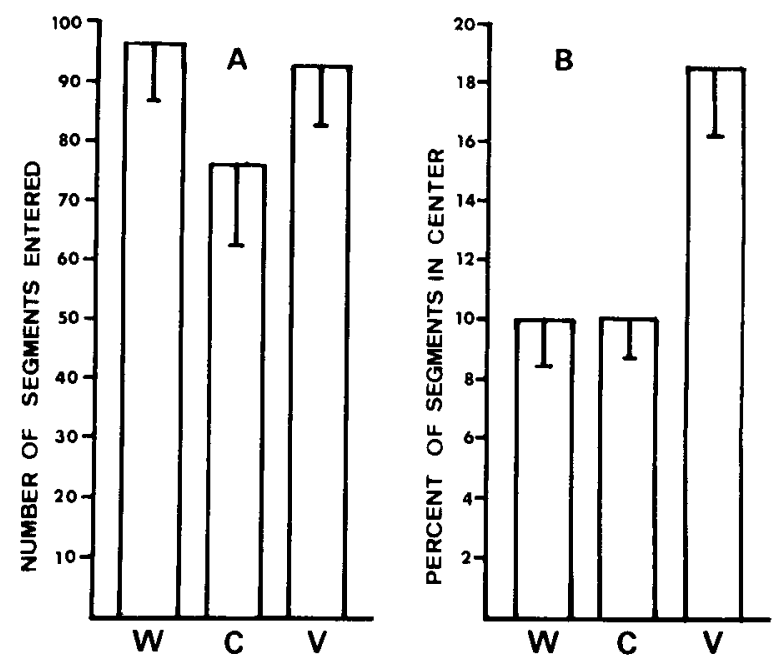

Figure 1. Number of segments entered (Panel A) and percent of segments entered in the center of the open field (Panel B) during a single 5-min test following preexposure to familiar tap water (W), novel coffee $(C)$, or a variable series of flavored solutions (V). Perpendicular lines are group standard errors of the mean.

field approximately $10 \%$ of the time, while animals in Group $\mathrm{V}$ were active in this part of the apparatus approximately $20 \%$ of the time. Informal observations showed that, following placement in the center circle, animals in Groups $W$ and $C$ tended to leave almost immediately from that point and, with little exploratory movement, ambulate directly to the wall. Thus, the majority of the $10 \%$ of the segments entered in the center of the field were crossed as the animals went from the center of the field to the periphery. In contrast, animals in Group V tended to explore the center section of the field and return to many segments already entered in the central part of the open field before they reached the periphery.

Analysis on the amount of rearing by means of a single-factor ANOVA revealed differences among the groups that were not statistically reliable $[\mathrm{F}(2,15)$ $<1]$. The lack of statistical reliability of this measure is not surprising, since frequency of rearing has been shown to be highly correlated with ambulation scores (Ivinskis, 1968) and in the previous analysis it was discovered that overall activity did not differ among the groups. However, a single-factor ANOVA on the number of bouts of grooming showed that there were differences among the groups $[F(2,15)=5.50$,

Table 1

Mean Amount of Rearing and Grooming During a 5-Min Open-Field Test

\begin{tabular}{lcccc}
\hline & \multicolumn{2}{c}{ Rearing } & \multicolumn{2}{c}{ Grooming } \\
& Mean & SEM & Mean & SEM \\
\hline Water & 15.50 & 1.82 & 2.33 & .56 \\
Coffee & 16.83 & 1.76 & .50 & .22 \\
Variable & 18.17 & 2.61 & .83 & .43 \\
\hline
\end{tabular}


$p<.011$. Newman-Keuls comparisons among the groups showed that animals in Group W exhibited reliably more grooming than either of the other groups (all ps $<.01$ ) while Groups $\mathrm{V}$ and $\mathrm{C}$ did not differ from each other. The fact that animals in Group W exhibited reliably more grooming than animals in the other groups can be interpreted to indicate the greater timidity of these animals (e.g., Walsh \& Cummins, 1976). Inspection of Table 1 , however, reveals that animals in all groups showed very little signs of grooming. Therefore, although there may have been reliable statistical differences among the groups, these differences may not be meaningful behaviorally, a conclusion which is consistent with findings reported by other investigators (e.g., Ivinskis, 1968).

The results of this experiment indicated that, overall, there were no activity differences among the animals in the various groups. However, animals that had experienced the variety of tastes exhibited reliably more activity in the central part of the open field than animals in either of the other groups and, therefore, can be considered to be less emotionally reactive than animals that had received preexposure to familiar tap water or to the taste of coffee. Interpreted in this way, the present findings suggest that preexposure to a variable series of flavored solutions not only reduces animals' neophobic tendencies towards other flavored solutions (e.g., Braveman \& Jarvis, 1978; Capretta et al., 1975), but also appears to influence exploratory behavior in a novel situation by reducing emotionality.

\section{EXPERIMENT 2}

It has been observed that both wild and laboratoryreared rats will refuse to consume a familiar food from a novel container (e.g., Barnett, 1963). The reason for this type of baitshyness is presumed to be the results of emotional reactivity that is produced by the novel container. If, as indicated by the results of the previous experiment, animals that have had preexposure to a variety of novel flavors are less emotionally reactive to novel environmental stimuli than animals that have had previous experience with a single novel flavor or with a familiar solution, then it is also possible that animals given variable preexposure may be more likely to consume a familiar substance from a novel container than animals that have been exposed to a single novel flavor or to a familiar flavor. In the present experiment, this possibility was examined by presenting animals with familiar tap water from a drinking cup instead of from their normal water bottle following preexposure to tap water, coffee solution, or the variable series of solutions used in the previous experiment.

\section{Method}

Subjects. The subjects were 18 experimentally naive male rats of the Long-Evans strain that were obtained from a commercial breeder. Animals were housed as in the previous experiment and weighed between 250 and $300 \mathrm{~g}$ at the start of the experiment.

Apparatus and Procedure. All unspecified details of the present experiment were the same as those in the previous experiment.

Following a 14-day adaptation period to the restricted drinking schedule, animals in Group W (water $=6$ ) were given $10 \mathrm{ml}$ of tap water per day via standard drinking bottles in their home cages; those in Group $\mathrm{C}$ (coffee $=6$ ) received eight daily presentations of the coffee solution; and those in Group V (variable $=6$ ) received eight daily random presentations of the saccharin, lemon, almond, and coffee solutions. On Day 23, all animals were presented with tap water from their normal drinking bottles for $10 \mathrm{~min}$. Each bottle contained $25 \mathrm{ml}$ of tap water at room temperature. During their normal drinking time on the following day, the animals were once again presented with tap water. This time, however, the water was presented in a stainless steel drinking cup (approximately $5 \mathrm{~cm}$ in radius and $6 \mathrm{~cm}$ deep) which could be fastened to the bottom of the home cage and which contained $25 \mathrm{ml}$ of tap water at room temperature. Prior to this test, the animals had never consumed any liquid from the drinking cup. The amount consumed on both occasions was measured to the nearest $0.1 \mathrm{ml}$ on both Day 23 and Day 24 drinking tests.

\section{Results and Discussion}

The results of the two drinking tests are summarized in Figure 2. For each pair of histograms, the one on the left represents the amount of tap water that animals drank from their normal drinking bottle on Day 23 and the one on the right represents the amount that they consumed from the drinking cup on Day 24. A single-factor ANOVA on the amount consumed from the bottle revealed that the differences among the three groups were not reliable $[\mathrm{F}(2,15)<1]$. A

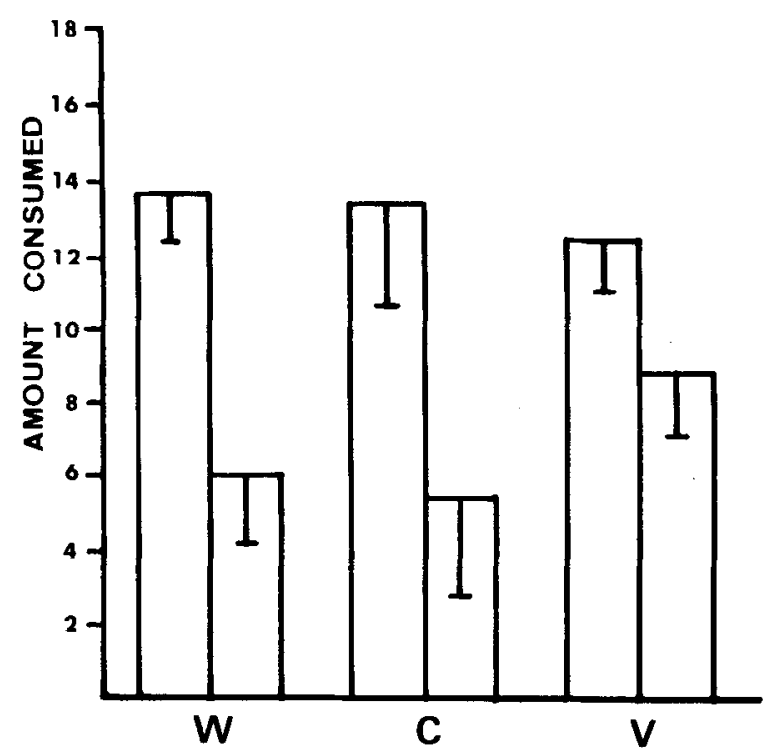

Figure 2. Amount of familiar tap water consumed from a familiar container (left histogram of each pair) or from a novel drinking cup (right histogram of each pair) following preexposure to familiar tap water $(W)$, novel coffee $(C)$, or a variable series of flavored solutions (V). Perpendicular lines are group standard errors of the mean. 
similar ANOVA on the amount consumed from the drinking cup showed that there were reliable differences among the means $[\mathrm{F}(2,15)=7.19, \mathrm{p}<.01]$. Newman-Keuls comparisons on the three means showed that animals in Group V drank reliably more than animals in the other two groups (all ps $<.01$ ), while Groups W and $C$ did not differ from each other.

These results show that animals that have received variable experience with tastes drink more, in absolute amounts, of a familiar solution from a novel container than do animals that have not experienced novel, distinctively flavored solutions and more than animals that have experienced only one novel distinctively flavored solution. It is also apparent from the results of the Day 23 test that the different types of preexposure experiences had no reliable effects on the intake of a familiar solution from a familiar container. In fact, because of this latter finding, it is not likely that animals drank different amounts on Day 24 from the cups because they were differentially thirsty. Thus, it appears that one way to disrupt the natural tendency to avoid eating a familiar substance from a novel container is to provide the animal with variable taste experiences.

\section{EXPERIMENT 3}

The results of the present experiments along with those previously cited suggest that there might be an interaction between eating-related stimuli. It appears that animals that have been preexposed to one set of stimuli (e.g., tastes or odors) are less neophobic to ingestibles that are characterized by another set of stimuli (e.g., the characteristics of the food container) than are animals that have not been preexposed. One set of stimuli which appear to play a potentially important role in the normal process of food selection are those cues which characterize the place in which animals typically eat. It is known that consumption of a normal food substance in laboratory and wild rats can be disrupted by shifting the place where animals usually eat (e.g., Barnett, 1963). Moreover, Rudy, Rosenberg, and Sandell (1977) have shown that environmental cues may interact with taste cues, since the introduction of novel environmental stimuli can disrupt the interference in taste aversion conditioning that typically follows preexposure to the test solution. However, no experiment has been reported in which the effects of preexposure to different feeding places on taste neophobia has been examined.

The purpose of the present experiment, then, was to discover possible cross-modality effects of environmental and taste cues by preexposing animals to different feeding environments and then examining their response to a novel saccharin solution in a familiar feeding environment. In this experiment, the animals consumed familiar tap water in their home cages, in plastic mouse cages, in wooden boxes painted white, or in a random sequence of all three. Tests for neophobia to novel saccharin water were then administered in animals' home cages.

\section{Method}

Subjects. The subjects were 24 experimentally naive male rats of the Long-Evans strain obtained from a commercial breeder. The animals were housed as in previous experiments and weighed between 250 and $300 \mathrm{~g}$ at the start of the experiment.

Apparatus and Procedure. All procedural details, except where noted, were the same as those used in the previous experiments.

For 21 days (Days $15-35$ of the experiment) after adaptation to handling and to the restricted drinking schedule, the animals in Group HC (home cage $=6$ ) continued to receive $10 \mathrm{ml}$ of tap water per day from the normal drinking bottle in their home cages. Animals in Group MC (mouse cage $=6$ ) received $10 \mathrm{ml}$ of tap water per day from their normal drinking bottles in a plastic mouse cage which measured $12 \times 12 \times 25 \mathrm{~cm}$ and was located away from the housing quarters. Animals in Group WC (wooden cage $=6$ ) received their daily $10-\mathrm{ml}$ ration of tap water from water bottles in a white wooden cage $(36 \times 31 \times 20 \mathrm{~cm})$, which was fitted with a wire-mesh floor and which was also located in a different part of the laboratory. Finally, animals in Group V (variable $=6$ ) received their daily $10 \mathrm{ml}$ of tap water in the mouse cage, in the wooden cage, or in the home cage. The order for each animal in Group $\mathrm{V}$ was determined by a random sequence that was constrained by the fact that, over the 21-day period, the animals drank in each of the environments on seven different occasions.

On Day 36, all animals were allowed to drink tap water for $10 \mathrm{~min}$ from the normal drinking bottles located in their home cages. On Day 37, the drinking bottles, which contained $.15 \%$ $(w / v)$ saccharin water, were once again placed on each of the home cages and the animals were allowed to drink for $10 \mathrm{~min}$. The amount consumed on each of these 10-min tests was recorded to the nearest $0.1 \mathrm{ml}$.

\section{Results and Discussion}

The results of this experiment are summarized in Figure 3 in terms of the amount consumed by the

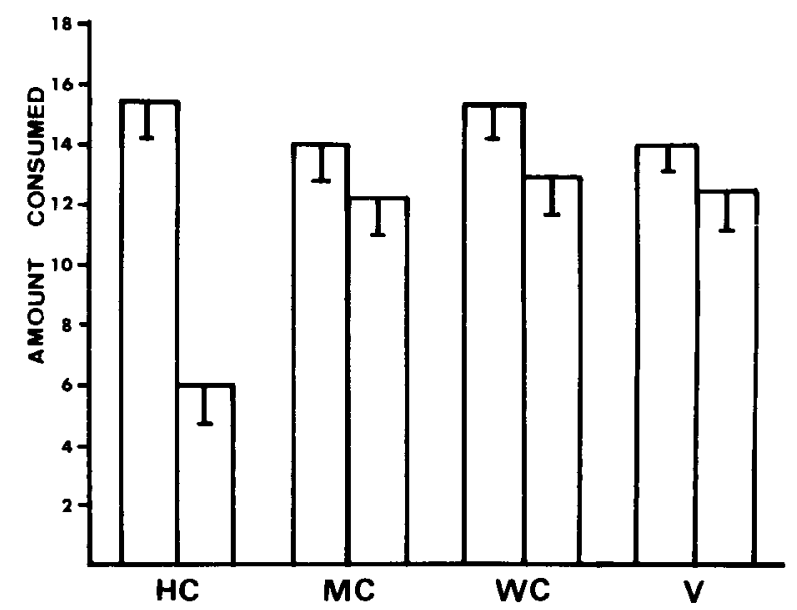

Figure 3. Amount of familiar tap water (left histogram of each pair) and novel saccharin water (right histogram of each pair) consumed following drinking experiences in the home cage (HC), a novel mouse cage (MC), a novel wooden cage (WC), or in a variety of locations (V). Perpendicular lines are group standard errors of the mean. 
animals on each of the two 10 -min tests. For each pair of histograms, the one on the left represents the amount of tap water consumed on Day 36 while the one on the right represents the amount of saccharin water consumed on Day 37. A single-factor ANOVA on the amount of tap water consumed revealed that the differences among the groups were not reliable $[F(3,20)<1]$. This finding indicated that preexposure to the various drinking environments did not influence intakes of familiar water and that any differences in consumption of saccharin water that might occur on Day 37 was not likely to have resulted from differential thirst among the groups.

A single-factor ANOVA on the amount of saccharin water consumed on Day 37 revealed differences that were statistically reliable $[\mathrm{F}(3,20)=8.62, \mathrm{p}<.01]$. Newman-Keuls comparisons on the means revealed that animals that had been preexposed to the tap water in their home cages (Group HC) drank reliably less of the saccharin water than animals in any of the other groups (all ps $<.01$ ), while Groups MC, WC, and $V$ did not differ from each other. Inspection of Figure 3 shows that animals that had been exposed to the tap water in any of the environments outside of the home cage consumed almost as much saccharin water as they had consumed of familiar-tasting tap water from the familiar water bottles. This observation, along with the outcome of the Day 37 test, suggests that preexposure to any of the feeding environments totally disrupted the taste-neophobia response. Thus, the results of the present experiment show that it is possible to disrupt an animal's neophobic tendency toward a novel tasting substance by providing the animal with feeding experiences outside of the normal feeding environment.

\section{GENERAL DISCUSSION}

The results of Experiments 2 aqnd 3 show that at least two kinds of feeding preexposure experiences can have selective effects on subsequent intake of fluids. That is to say, the preexposure effects that were involved in these experiments appear to have been restricted only to the intake of novel-flavored solutions or to familiar solutions that were presented in novel containers. In neither of these experiments, for example, did any of the preexposure manipulations appear to influence the intake of familiar tap water from a familiar container. Taken together with results of other experiments, these findings appear to be further support for the cross-modality or nonspecific effects of preexposure on neophobia. In the present experiments, preexposure to novel taste cues was shown to disrupt neophobia to a familiar solution that was consumed from a novel container while preexposure to novel drinking environments disrupted taste neophobia. Thus it appears that not only is it possible to reduce neophobia to one flavored solution by preexposing animals to a discriminably different flavored solution, but it also appears to be possible to reduce taste neophobia by manipulations which involve other classes of stimuli (e.g., odors, feeding environments, and handling).

The results of Experiment 1, in conjunction with findings reported by several other investigators, suggest a mechanism by which these preexposure effects can be understood. In Experiment 1, it was reported that, having had taste preexposure to a variety of flavored solutions, animals were less emotionally reactive than those that did not experience the same degree of dietary diversity. These findings suggest that those and other preexposure phenomenon may be mediated by reduced emotional reactivity. In this regard, it is interesting to note that animals that have been handled in infancy tend, as adults, not only to exhibit reduced neophobia (Weinberg et al., 1978) but also are less emotionally reactive (Ader, 1965) and also show less of a corticosterone response to novel stimulation than do nonhandled controls (Ader, 1975). By inference, then, it is possible that preexposure to various tastes, odors, drinking environments, or handling reduces emotional reactivity to, and perhaps the aversiveness of, other novel stimuli, such as distinctively flavored novel solutions or novel containers. This change in emotional reactivity may be mediated by changes in the adrenocortical system which can be produced by the different preexposure experiences. One possible exception to the proposed role of pituitary-adrenal mediation is that Smotherman and Levine (1978) report no rise in plasma levels of corticosterone following the test presentation of a milk solution to rats. There are, however, two points worth noting in this regard. First, it is not clear from these experiments whether or not animals presented with the milk solution for the first time are neophobic to it. Results of independent experiments of Cappretta and Rawls (1974) and Galef and Henderson (1972) indicate that the taste of the mother's milk can have long-range effects on adults' food preferences. Thus, it is possible that the similarity in the taste of the milk test solution used by Smotherman and Levine (1978) and the taste of the mother's milk or the procedure of preexposing animals to the milk solution prior to the critical tests may have precluded a neophobic response in that study. Secondly, the conclusion that changes in plasma levels of corticosterone are independent of neophobic responses is based on a single sampling of plasma which occurred 10 min after the end of the drinking test and clearly contradict findings reported by Ader (1976), who reported nonconditioned rises in plasma corticosterone when animals were also exhibiting a strong neophobic response to novel saccharin water. It is possible that Smotherman and 
Levine (1978) would have observed the correlated rise in corticosterone had they sampled plasma at another time and/or had they used another test solution. Certainly, more research is required before one can rule out the role of pituitary-adrenal mediation of the preexposure phenomena reported in the present experiments.

Thus, in terms of the context provided by Capretta et al. (1975), it is possible that the effects of early dietary diversity are a special example of a more general class of behaviors in which prior experience with novel stimulation reduces general smotional reactivity to all novel stimuli, perhaps by producing changes in adrenocortical functioning. If subsequent research substantiates this speculation, it would provide empirical support for Domjan's (1976) notion that a single mechanism mediates a variety of preexposure phenomena.

\section{REFERENCES}

ADER, R. A. Effects of eariy experience and differential housing on behavior and susceptibility to gastric erosions in the rat. Journal of Comparative and Physiological Psychology, 1965, 60, 233-238.

ADER, R. A. Early experience and hormones: Emotional behavior and adrenocortical function. In B. E. Eleftheriou \& R. L. Sprott (Eds.), Hormonal correlates of behavior (Vol. I). New York: Plenum Press, 1975. Pp. 7-33.

ADER, R. A. Conditioned adrenocortical steroid elevations in the rat. Journal of Comparative and Physiological Psychology, 1976, 90, 1156-1163.

BARnetT, S. A. The rat: A study in behavior. Chicago: Aldine, 1963.

Braveman, N. S., \& JARvis, P. J. Independence of neophobia and taste aversion learning. Animal Learning \& Behavior, 1978, 6. $406-412$.

BroaDhuRst, P. L. Determinants of emotionality in the rat. I. Situational factors. British Journal of Psychology, 1957, 48, 1-12.
CAPRETtA, P. J., \& RAWLS, L. J., III. Establishment of a flavor preference in rats: Importance of nursing and weaning exper. iences. Journal of Comparative and Physiological Psychology, 1974, 86, 670-673.

Capretta, P. J., Petersik, T. T., \& Stewart, D. J. Acceptance of novel flavor is increased after early experiences with diverse tastes. Nature, 1975, 254, 689-694.

Doman, M. Determinants of the enhancement of flavor-water intake by prior exposure. Journal of Experimental Psychology: Animal Behavior Processes, 1976, 2, 17-27.

Galef, B. G., JR., \& Henderson, P. W. Mother's milk: A determinant of the feeding preferences of weanling rat pups. Journal of Comparative and Physiological Psychology, 1972, 78, 213-219.

Hennessy, M. B., Smotherman, W. P., \& Levine, S. Early olfactory enrichment enhances later consumption of novel substances. Physiology \& Behavior, 1977, i9, 481-483.

IVINSKIs, A. The reliability of behavioral measures obtained in the open field. Australian Journal of Psychology, 1968, 20, 173-177.

McCall, R., Lester, M., \& Dolan, C. Differential rearing and the exploration of stimuli in the open field. Developmental Psychology, 1969, 1, 750-762.

Rudy, J., Rosenberg, L., \& Sandell, J. H. Disruption of a taste familiarity effect by novel exteroceptive stimulation. Journal of Experimental Psychology: Animal Behavior Processes, 1977, 3, 26-36.

SIEGEL, S. Flavor preexposure and "learned safety." Journal of Comparative and Physiological Psychology, 1974, 87, 1073-1082.

Smotherman, W. P., \& LeVine, S. ACTH and ACTH4-10 modification of neophobia and taste aversion responses in the rat. Journal of Comparative and Physiological Psychology, 1978, 92 , 22-33.

VALLE, F. P. Effects of strain, sex and illumination on open field behavior of rats. American Journal of Psychology, 1970, 83, 103-111.

Walsh, R. N., \& Cummins, R. A. The open field test: A critical review. Psychological Bulletin, 1976, 83, 482-504.

Weinberg, J., SMotherman, W. S., \& LeVine, S. Early handling effects on neophobia and conditioned taste aversions. Physiology \& Behavior, 1978, in press.

(Received for publication March 10, 1978; revision accepted May $9,1978$. ) 